\title{
Metformin regulation of progesterone receptor isoform-B expression in human endometrial cancer cells is glucose-dependent
}

\author{
SOFIA JADE U. SAGUYOD ${ }^{1}$, IAD ALHALLAK ${ }^{2}$, ROSALIA C.M. SIMMEN ${ }^{2,3}$ and MICHAEL C. VELARDE ${ }^{1}$ \\ ${ }^{1}$ Institute of Biology, College of Science, University of the Philippines Diliman, Quezon City, PH 1101, Philippines; \\ ${ }^{2}$ Department of Physiology and Biophysics and ${ }^{3}$ The Winthrop P. Rockefeller Cancer Institute, \\ University of Arkansas for Medical Sciences, Little Rock, AR 72205, USA
}

Received March 19, 2020; Accepted August 25, 2020

DOI: $10.3892 / \mathrm{ol} .2020 .12112$

\begin{abstract}
Metformin (MET) constitutes the first-line treatment against type 2 diabetes. Growing evidence linking insulin resistance and cancer risk has expanded the therapeutic potential of MET to several cancer types. However, the oncostatic mechanisms of MET are not well understood. MET has been shown to promote the expression of progesterone receptor (PGR) and other antitumor biomarkers in patients with non-diabetic endometrial cancer (EC) and in Ishikawa EC cells cultured in normal glucose $(5.5 \mathrm{mM})$ media. Therefore, the present study aimed to assess the effects of MET on EC cells under conditions simulating diabetes. Ishikawa cells treated with $10 \mathrm{nM}$ $17 \beta$-estradiol (E2) and/or $100 \mu \mathrm{M}$ MET and exposed to normal and high $(17.5 \mathrm{mM})$ concentrations of glucose were evaluated for proliferative and $P G R$ expression status. Under normal glucose conditions, MET attenuated E2-induced cell proliferation and cyclin D1 gene expression, and increased total $P G R$ and $P G R-B$ transcript levels. MET inhibited Ishikawa cell spheroid formation only in the absence of E2 treatment. In E2-treated cells under high glucose conditions, MET showed no effects on cell proliferation and spheroid formation, and increased total $P G R$ but not $P G R-B$ transcript levels. Transfection with Krüppel-like factor 9 small interfering RNA increased $P G R$ - $A$ transcript levels, irrespective of glucose environment. Medroxyprogesterone acetate downregulated $P G R-A$ expression more effectively with metformin under high compared with normal glucose conditions. To evaluate
\end{abstract}

Correspondence to: Professor Michael C. Velarde, Institute of Biology, College of Science, University of the Philippines Diliman, Regidor Street, National Science Complex, Quezon City, PH 1101, Philippines

E-mail: mcvelarde@up.edu.ph

Professor Rosalia C.M. Simmen, Department of Physiology and Biophysics, University of Arkansas for Medical Sciences, 4301 W Markham Street Slot 750, Little Rock, AR 72205, USA

E-mail: simmenrosalia@uams.edu

Key words: metformin, Ishikawa cells, PGR, estrogen, AMP-activated protein kinase the potential mechanisms underlying the targeting of PGR by MET, E2-treated cells were incubated with MET and the AMPK inhibitor Compound C, or with the AMPK activator 5-aminoimidazole-4-carboxamide ribonucleotide (AICAR), under normal glucose conditions. Compound $\mathrm{C}$ abrogated the effects of MET on $P G R-B$ while AICAR increased $P G R-B$ transcript levels, albeit less effectively compared with MET. The present results demonstrate the glucose-dependent effects of MET on $P G R-B$ isoform expression, which may inform the response to progestin therapy in diabetic women with EC.

\section{Introduction}

Endometrial cancer (EC) is the sixth most commonly occurring cancer in women, with an incidence rate rising to $3.5 \%$ of all new cancer cases and representing $2 \%$ of all cancer deaths in the USA (1). While the 5-year survival rate for patients with EC in economically advantaged countries is high $(\sim 80 \%)$ compared with those for patients with other female-associated types of cancer, such as breast and ovarian cancer, the prognosis for women with EC is dismal in other parts of the world where treatment options are limited. The metabolic disorders type 2 diabetes and obesity are increasingly linked to an increased risk of cancer, including EC (2-4). The estimated type 2 diabetes incidence rate for 2019 is $9.3 \%$ globally (5). Furthermore, $35-40 \%$ of adults are obese in the USA and the worldwide prevalence of obesity has tripled to $13 \%$ over a timespan of 40 years (6). The staggering financial and personal burdens of cancer underscore the need for the development of novel therapeutic and preventative strategies that are clinically effective and financially deliverable to the general population.

Metformin (1,1-dimethylbiguanide hydrochloride; MET) constitutes the first-line treatment for type 2 diabetes. Previous studies have highlighted the therapeutic value of MET as an adjuvant treatment in breast cancer (7). EC is pathologically akin to breast cancer since it is steroid hormone-driven, tightly linked to abnormal glucose metabolism and insulin signaling, and exhibits a complex, multi-factorial origin. In breast cancer cells, MET has been shown to inhibit cell proliferation, invasion and inflammation, promote apoptosis and exert a cytotoxic effect on cancer stem cells $(8,9)$. Nevertheless, the anti-breast cancer benefits of MET have been inconsistent and appear to be dependent on context and the duration of exposure. In triple 
negative breast cancer cell lines for example, glucose levels in the diabetic range diminished the effects of MET on cell proliferation, cell death and cell cycle arrest (10). Conversely, glucose starvation enhanced the inhibitory effect of MET on the mTOR pathway, a downstream target of AMP-activated protein kinase (AMPK) and an activator of growth factor signaling in breast cancer cells (11). Moreover, breast cancer cells chronically exposed to MET acquired resistance to the drug, which was accompanied by changes in the expression of key genes and resulted in the generation of a metastatic stem-cell like phenotype (12).

In a previous study, it was shown that the short-term treatment of non-diabetic and obese women with MET during the pre-surgical window between diagnosis and hysterectomy promoted the expression of antitumor biomarkers; this effect was recapitulated in Ishikawa human endometrial cancer cells treated with a physiological dose of MET under normal glucose conditions (13). While these results support the ability of MET to reduce EC risk and development, meta-analyses of current clinical data indicate conflicting MET outcomes, with some showing no effect (14) and others showing inhibitory effects (15). In light of the findings for breast cancer, a strong rationale exists for clarifying the ambiguities regarding the context and dosage at which MET exerts its optimal therapeutic effects in EC to achieve its potential for clinical use.

In humans treated with a single 500-mg dose of MET, the blood concentration of MET $2.4 \mathrm{~h}$ post-oral intake was $4 \mu \mathrm{M}$, as measured by high-pressure liquid chromatography (16). In mice, the oral administration of MET at $50 \mathrm{mg} / \mathrm{kg}$ body weight resulted in a MET concentration of $10-70 \mu \mathrm{M}$ in the portal vein and $10-40 \mu \mathrm{M}$ in the plasma, as measured using 14C-radiolabeled MET (17). Thus, studies that use $\mathrm{mM}$ concentrations of MET may not be physiologically relevant. In the present study, estrogen-treated Ishikawa EC cells were characterized for their response to $100 \mu \mathrm{M}$ MET and glucose concentrations typifying the non-diabetic and diabetic ranges, using progesterone receptor $(P G R)$ gene expression as the primary outcome. The present findings demonstrate the glucose-dependency of the MET-mediated effects on $P G R$ isoform $\mathrm{B}(P G R-B)$ expression, which may be relevant when assessing the response to progestin-based therapy of diabetic and non-diabetic patients with EC and other gynecological pathologies.

\section{Materials and methods}

Cell culture and treatments. The Ishikawa human endometrial epithelial carcinoma cell line (a gift from Dr Bruce Lessey, Greenville Health System; Prisma Health) was authenticated and propagated as previously described (13). Cells were initially grown in Minimal Essential Media (MEM; Gibco; Thermo Fisher Scientific, Inc.), supplemented with $10 \%$ (v/v) fetal bovine serum (FBS; Gibco; Thermo Fisher Scientific, Inc.) and containing phenol red and $1 \%$ antibiotic-antimycotic solution (Invitrogen; Thermo Fisher Scientific, Inc.) in a humidified incubator $\left(5 \% \mathrm{CO}_{2} / 95 \%\right.$ air $)$ at $37^{\circ} \mathrm{C}$. In subsequent experiments incorporating various treatments, cells were incubated in either phenol red-free MEM or phenol red-free Dulbecco's modified Eagle's medium (DMEM)/Nutrient Mixture F-12 (DMEM/F-12), each supplemented with charcoal-stripped
$10 \%$ FBS and $1 \%$ antibiotic-antimycotic solution and referred to hereinafter as MEM-FBS and DMEM-FBS, respectively. MEM which contains $5.5 \mathrm{mM}$ glucose represents the normal glucose environment while DMEM with $17.5 \mathrm{mM}$ glucose, typifies a high glucose environment.

MET (Sigma-Aldrich; Merck KGaA) was dissolved in phosphate-buffered saline (PBS; Gibco; Thermo Fisher Scientific, Inc.) and initially evaluated at final concentrations of 10 or $100 \mu \mathrm{M}$, which approximate the physiological range found in patients treated with MET for type 2 diabetes (18). $17 \beta$-estradiol (E2; Sigma-Aldrich; Merck KGaA) was dissolved in dimethyl sulfoxide (DMSO), further diluted in PBS and used at final concentrations of 0.1 or $10 \mathrm{nM}$. Medroxyprogesterone acetate (MPA; Sigma-Aldrich; Merck $\mathrm{KGaA}$ ) was dissolved in DMSO, further diluted in PBS and used at a final concentration of $1 \mu \mathrm{M}$. The AMPK activator, 5-aminoimidazole-4-carboxamide ribonucleotide (AICAR; Sigma-Aldrich; Merck KGaA) was dissolved in PBS and used at a final concentration of $500 \mu \mathrm{M}$. Compound $\mathrm{C}$ (dorsomorphin; Sigma-Aldrich; Merck KGaA), an AMPK inhibitor, was dissolved in DMSO, further diluted in PBS and used at a final concentration of $5 \mu \mathrm{M}$. In all treatment protocols where DMSO was added to solubilize E2, MPA and compound C, the same amount of DMSO was added to the control treatment. The various treatment strategies are summarized in Fig. 1.

Cell proliferation assay. Cells were seeded onto 96-well culture dishes at a density of $1 \times 10^{4}$ cells/well in MEM-FBS or DMEM-FBS. After $24 \mathrm{~h}$, cells were pre-treated with E2 $(0.1$ or $10 \mathrm{nM})$ or vehicle control (DMSO-PBS) and incubated for another $24 \mathrm{~h}$ at $37^{\circ} \mathrm{C}$. E2 was removed with a change of media and cells were then treated with MET (10 or $100 \mu \mathrm{M})$ or vehicle control (PBS) twice at 24 -h intervals at $37^{\circ} \mathrm{C}$. Cells were collected $24 \mathrm{~h}$ after the final MET treatment. Cell viability was evaluated by the Cell Counting Kit-8 (Dojindo Molecular Technologies, Inc.) metabolic assay according to the manufacturer's instructions. Absorbance at $450 \mathrm{~nm}$ was assessed using a CLARIOstar plate reader (BMG Labtech $\mathrm{GmbH}$ ) and the mean optical density from $n=4$ wells/treatment group was calculated. The cells treated with and without E2 $(10 \mathrm{nM})$ and in the presence or absence of MET $(100 \mu \mathrm{M})$ were collected and their cyclin D1 (CCND1) transcript levels were measured by reverse transcription-quantitative (q)PCR.

Spheroid-formation assay. Ishikawa cells were plated in 24-well ultra-low attachment plates (Corning Inc.) at a seeding density of $8 \times 10^{3}$ cells/well. The plating medium consisted of phenol red-free MEM or phenol red-free DMEM-F12 and was supplemented with B27 (Invitrogen; Thermo Fisher Scientific, Inc.), human basic fibroblast growth factor $(20 \mathrm{ng} / \mathrm{ml}$; Invitrogen; Thermo Fisher Scientific, Inc.), human epidermal growth factor $(20 \mathrm{ng} / \mathrm{ml}$; Invitrogen; Thermo Fisher Scientific, Inc.), heparin (10 $\mu \mathrm{g} / \mathrm{ml}$; Sigma-Aldrich; Merck KGaA), antibiotic-antimycotic solution (1\% v/v) and gentamicin $(100 \mu \mathrm{g} / \mathrm{ml}$; Sigma-Aldrich; Merck KGaA). Cells were treated with PBS alone or with MET $(100 \mu \mathrm{M})$ in the presence or absence of E2 $(10 \mathrm{nM})$ at seeding and incubated in a humidified incubator $\left(5 \% \mathrm{CO}_{2} / 95 \%\right.$ air) at $37^{\circ} \mathrm{C}$. Culture media, as appropriate for each treatment group, were replenished with $62.5 \mu 1$ medium representing $12.5 \%$ of the initial plating volume, on incuba- 
Table I. Primer sequences used for reverse transcription-quantitative PCR.

\begin{tabular}{|c|c|c|}
\hline Gene & Primer sequences $\left(5^{\prime}-3^{\prime}\right)$ & PCR product size, bp \\
\hline \multirow[t]{2}{*}{$A C T B$} & F: TCACCAACTGGGACGACATG & 244 \\
\hline & R: TCACCGGAGTCCATCACGAT & \\
\hline \multirow[t]{2}{*}{ CCNDI } & F: CTGGCCATGAACTACCTG & 483 \\
\hline & R: GTCACACTTGATCACTCTGG & \\
\hline \multirow[t]{2}{*}{$T B P$} & F: TCCACAGTGAATCTTGGTTGTAAAC & 102 \\
\hline & R: CCTCATGATTACCGCAGCAAA & \\
\hline \multirow[t]{2}{*}{$P G R$} & F: CCTTTGGAAGGGCTACGAAGT & 110 \\
\hline & R: GAGCTCGACACAACTCCTTTTTG & \\
\hline \multirow[t]{2}{*}{$P G R-B$} & F: CGACCCAGGAGGTGGAGAT & 105 \\
\hline & R: GAGGGAAAAGGGAAGGAGGAG & \\
\hline \multirow[t]{2}{*}{ ESRl } & F: CGGCATTCTACAGGCCAAATT & 111 \\
\hline & R: AGCGAGTCTCCTTGGCAGATT & \\
\hline \multirow[t]{2}{*}{ ESR2 } & F: CGATTACGCATCGGGATATCA & 136 \\
\hline & R: GCGCCGGTTTTTATCGATT & \\
\hline \multirow[t]{2}{*}{ KLF9 } & F: TGGCTGTGGGAAAGTCTATGG & 124 \\
\hline & R: CTCGTCTGAGCGGGAGAACT & \\
\hline \multirow[t]{2}{*}{$K L F 4$} & F: TTCCCATCTCAAGGCACACCT & 120 \\
\hline & R: TGTTTACGGTAGTGCCTGGTCA & \\
\hline
\end{tabular}

ACTB, $\beta$-actin; CCND1, cyclin D1; TBP, TATA-binding protein; PGR, progesterone receptor; ESR, estrogen receptor; KLF, Krüppel-like factor.

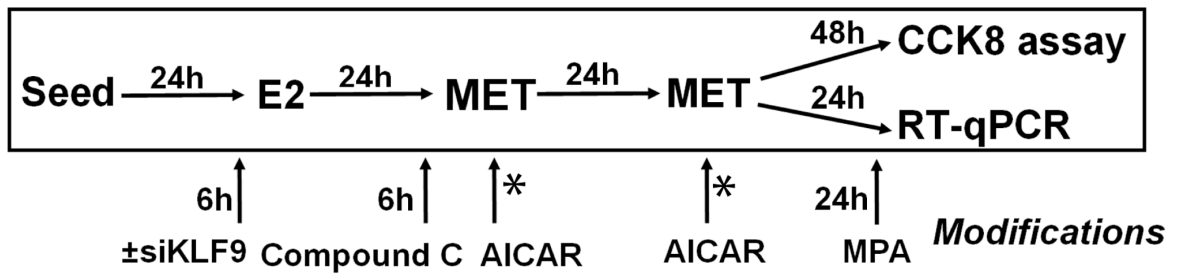

Figure 1. Schematic summary of treatment interventions in Ishikawa cells treated with MET in normal and high glucose culture media. Arrows indicate the time and duration of treatment interventions relative to E2 and MET administration. Asterisks indicate that AICAR was used in place of MET. MET, metformin; E2, 17ß-estradiol; CCK8, Cell Counting Kit-8; RT-qPCR, reverse transcription-quantitative PCR; siKLF9, small interfering RNA targeting Krüppel-like factor 9; AICAR, 5-aminoimidazole-4-carboxamide ribonucleotide; MPA, medroxyprogesterone acetate.

tion day 3. On day 5, non-adherent spheroids, designated as endospheres, with diameters $>60 \mu \mathrm{m}$ were counted manually using an Olympus IMT-2 inverted microscope (Olympus Corporation). In order to assess the self-renewal capacity of the primary endospheres, non-adherent spheroids from the first plating (passage 1, P1) were collected, dissociated into single-cell suspensions with $0.05 \%$ trypsin (Invitrogen; Thermo Fisher Scientific, Inc.), filtered using a $40-\mu \mathrm{m}$ sieve, and re-plated in MEM or DMEM-F12 supplemented as described for the plating medium, in ultra-low attachment plates with no further E2 or MET treatments. Endospheres with diameters $>60 \mu \mathrm{m}$, designated as passage 2 (P2), were counted after incubation for 5 days, with addition of fresh media (MEM or DMEM) on day 3.

RNA isolation and gene expression assay. Ishikawa cells were plated in 6-well plates (Falcon) at a density of $1.5 \times 10^{5}$ cells/well in MEM-FBS or DMEM-FBS for $24 \mathrm{~h}$ and treated with various reagents, following the timeline summarized in Fig. 1.
For all RNA analyses, cells were collected $24 \mathrm{~h}$ after the final MET treatment. RNA isolation, preparation of cDNAs and qPCR analyses were performed as previously described (19), using the geometric mean of $\beta$-actin and TATA-binding protein mRNAs as normalization controls. Primers (Table I), designed to span introns, were synthesized by Integrated DNA Technologies, Inc. qPCR was conducted using the CFX96 ${ }^{\mathrm{TM}}$ Real-Time PCR System (Bio-Rad Laboratories, Inc.) under the following thermocycling conditions: $30 \mathrm{sec}$ at $95^{\circ} \mathrm{C}$, followed by 39 cycles of $5 \mathrm{sec}$ at $95^{\circ} \mathrm{C}$ and $30 \mathrm{sec}$ at $60^{\circ} \mathrm{C}$, and a melt curve protocol of $5 \mathrm{sec}$ at $65^{\circ} \mathrm{C}$ with a gradual increase in temperature to $95^{\circ} \mathrm{C}$ by $0.5^{\circ} \mathrm{C}$ increments. Normalized mRNA expression was calculated with CFX Manager Software version 3.1.1517.0823 (Bio-Rad Laboratories, Inc.) using the $2^{-\Delta \Delta \mathrm{Cq}}$ method (20).

Transient transfection with small interfering (si)RNAs. Ishikawa cells were transfected with human Krüppel-like factor 9 (KLF9) siRNAs (siKLF9), following previously 

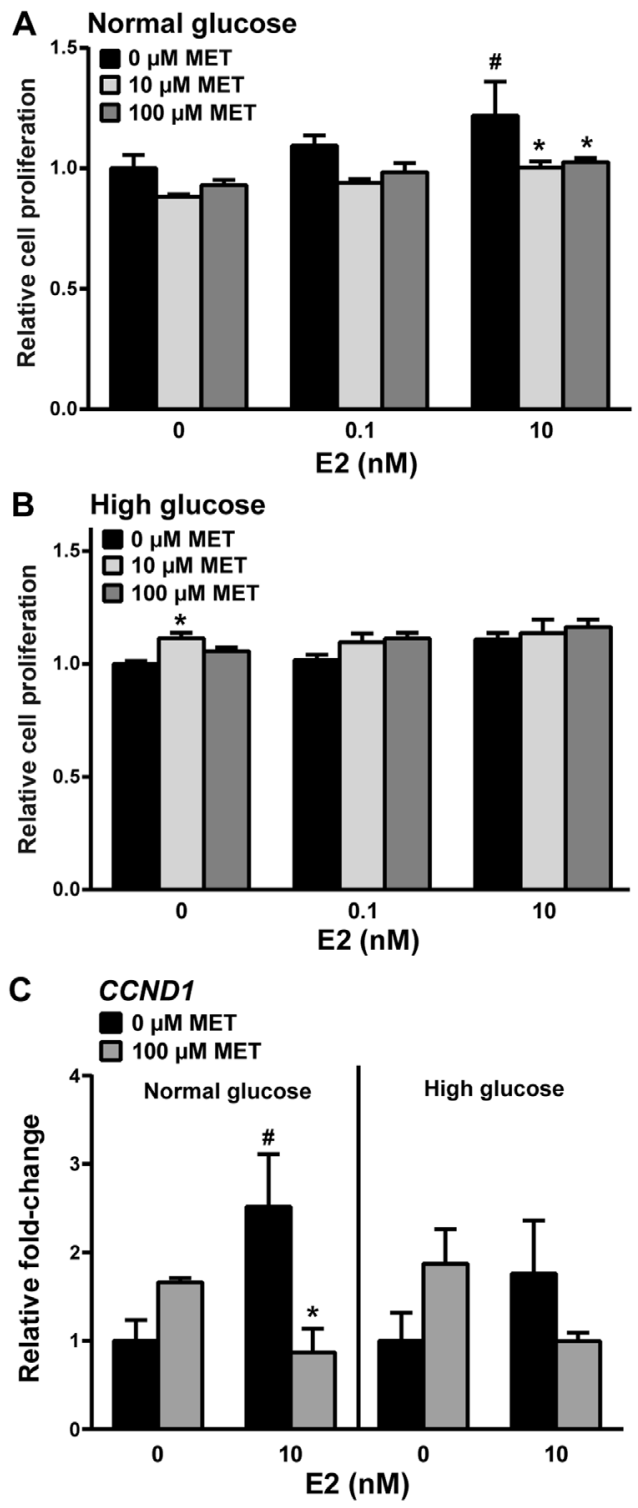

Figure 2. MET at physiologically relevant doses decreases the proliferation of E2-treated Ishikawa cells under normal but not high glucose culture conditions. Ishikawa cells cultured in media with (A) normal or (B) high glucose concentrations $(n=4)$ were treated with $(0.1$ and $10 \mathrm{nM})$ or without $(0 \mathrm{nM})$ E2 and then with $(10$ and $100 \mu \mathrm{M})$ or without $(0 \mu \mathrm{M})$ MET twice at 24-h intervals prior to the assessment of relative cell proliferation as fold-change relative to vehicle control. (C) Transcript levels of CCND1 were quantified by reverse transcription-quantitative PCR. TATA-binding protein and $\beta$-actin mRNAs were used as normalization controls. Data are presented as mean $\pm \operatorname{SEM}(\mathrm{n}=6)$ and are expressed as fold-change from the corresponding control ( $0 \mathrm{nM} \mathrm{E} 2$ and $0 \mu \mathrm{M}$ MET). ${ }^{*} \mathrm{P}<0.05$ vs. $0 \mu \mathrm{M}$ MET; ${ }^{\# P}<0.05$ vs. $0 \mathrm{nM}$ $\mathrm{E} 2$, as determined by two-way analysis of variance followed by Tukey's test. MET, metformin; E2, 17ß-estradiol; CCND1, cyclin D1.

described protocols (21). Briefly, cells were seeded in 6-well plates at a density of $1.5 \times 10^{5}$ cells/well in MEM-FBS or DMEM-FBS without added antibiotic for $24 \mathrm{~h}$. Cells were then transfected with Lipofectamine ${ }^{\circledR}$ 2000/OPTI-MEM I (Invitrogen; Thermo Fisher Scientific, Inc.) containing $50 \mu \mathrm{M}$ siKLF9 RNA pools (cat. no. L-011223-00-0005) or non-targeting (scrambled control, cat. no. D-001810-01-05) siRNAs (GE Healthcare Dharmacon, Inc.). After $6 \mathrm{~h}$ of transfection, cells were incubated for $24 \mathrm{~h}$ in MEM-FBS or DMEM-FBS containing 1\% antibiotic-antimycotic solution, and then treated with $\mathrm{E} 2(10 \mathrm{nM})$ for $24 \mathrm{~h}$, followed by MET $(100 \mu \mathrm{M})$ twice at $24-\mathrm{h}$ intervals at $37^{\circ} \mathrm{C}$. RNA isolation and gene expression analysis of cells collected $24 \mathrm{~h}$ after the last MET treatment were performed by the aforementioned method.

Statistical analysis. Data are presented as the mean \pm SEM and were analyzed for statistical differences between two groups using Student's t-test, and among three or more groups using two-way analysis of variance followed by Tukey's post hoc test. Analyses were performed using SigmaStat (version 3.5; Systat Software, Inc.). $\mathrm{P}<0.05$ was considered to indicate a statistically significant difference.

\section{Results}

MET inhibits proliferation of Ishikawa cells in normal but not high glucose conditions. Previous studies showed that MET decreased the viability of EC cells exposed to E2 $(22,23)$; however, those studies used supra-physiological MET concentrations of $>5 \mathrm{mM}$, which do not reflect the systemic $\mu \mathrm{M}$ concentrations detected in patients receiving MET (18). In order to evaluate whether physiologically relevant concentrations of MET act directly on E2-responsive EC cells to influence their viability, the well-differentiated Ishikawa endometrial carcinoma cell line was treated with E2 and exposed to MET in normal and high glucose media. Without MET, $10 \mathrm{nM}$ E2-treated cells under normal glucose conditions exhibited increased cell viability (Fig. 2A); this was decreased to basal levels when 10 or $100 \mu \mathrm{M}$ MET was added. By contrast, the viability of E2-treated cells was not influenced by MET in the high glucose medium (Fig. 2B). Notably, treatment with 10 $\mu \mathrm{M}$ MET in the absence of E2 increased cell viability in the presence of a high concentration of glucose. Gene expression analyses for the proliferation marker cyclin D1 showed that E2 induced CCND1 transcript levels in the absence of MET and that MET reduced these E2-induced effects under normal glucose conditions. Similar effects of MET were not observed in high glucose conditions (Fig. 2C).

MET inhibits Ishikawa sphere formation in normal but not high glucose conditions. Spheres formed from Ishikawa cells grown under non-adherent conditions are considered to constitute EC stem-like cells, based on their characterized genotype and phenotype $(24,25)$. In other types of tumor, MET has been shown to selectively target cancer stem cells by decreasing sphere formation in vitro and tumor formation in vivo (26). To assess whether MET influences the formation of endometrial spheres under normal or high glucose conditions, Ishikawa cells that normally grow as monolayers in plastic culture dishes (Fig. 3A, top panel) were plated in low-attachment culture dishes to enable the formation of endospheres (Fig. 3A, bottom panel) and treated with $100 \mu \mathrm{M}$ MET in the presence or absence of $10 \mathrm{nM}$ E2. Without E2, MET significantly inhibited the growth of primary endospheres $(\mathrm{P} 1 ;>60 \mu \mathrm{m}$ diameter) under normal glucose conditions; however, this effect of MET was lost with the addition of E2 (Fig. 3B). By contrast, MET with and without E2, showed no inhibitory effect on basal P1-endosphere formation under high glucose conditions (Fig. 3C). P1-endospheres were collected and re-plated in low 

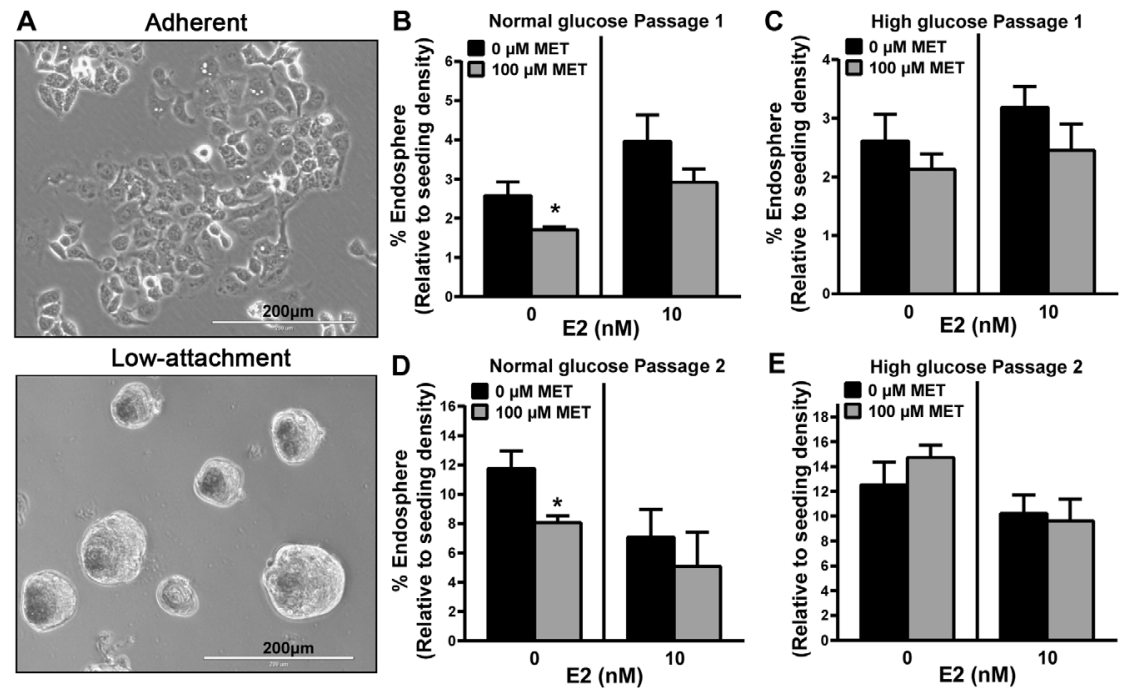

Figure 3. MET inhibits the sphere formation of Ishikawa cells under normal but not high glucose conditions. (A) Representative images show 2-dimensional (top panel) and 3-dimensional (bottom panel) growth of Ishikawa cells, when cultured in adherent and low-attachment culture plates, respectively. Ishikawa cells plated in low-attachment plates were treated with MET $(100 \mu \mathrm{M})$ in the presence or absence of E2 $(10 \mathrm{nM})$ at day 1 , under $(\mathrm{B})$ normal or $(\mathrm{C})$ high glucose conditions. At day 5, endometrial spheroids from the initial plating with a diameter of $>60 \mu \mathrm{m}$ were counted (designated passage 1). Non-adherent spheroids from passage 1 were collected, dissociated into single-cell suspensions with $0.05 \%$ trypsin, filtered using a $40-\mu \mathrm{m}$ sieve and re-plated in (D) normal or (E) high glucose conditions in ultra-low attachment plates with no further treatments. Endometrial spheroids with a diameter of $>60 \mu$ m were counted and designated passage 2. Data are presented as mean \pm SEM $(n=6)$ and expressed as $\%$ endosphere, calculated as the ratio of spheroids with a diameter of $>60 \mu \mathrm{m}$, relative to the total number of initial plated Ishikawa cells x100. " $\mathrm{P}<0.05$ vs. $0 \mu \mathrm{M}$ MET, as determined by Student's t-test. MET, metformin; E2, $17 \beta$-estradiol.

attachment plates in normal or high glucose conditions without further MET or E2 treatments. P2-endospheres exhibited increased formation efficiency (10-12 vs. 2-3\% for P1) when normalized to initial seeding density, indicating self-renewal (Fig. 3D and E). Moreover, P2-endospheres grown in normal and high glucose conditions exhibited responses to MET without and with added E2 that were comparable with those observed for the respective P1-endospheres.

MET-induced changes in total PGR and PGR-B transcript levels are dependent on glucose. We previously showed that MET inhibited the expression of the antitumor biomarker PGR in EC cells in vivo (protein) and in vitro (transcript) (13). Transcript levels of total $P G R$ and its antiproliferative isoform $P G R-B$ were evaluated in Ishikawa cells in response to $100 \mu \mathrm{M}$ MET, following a 24-h pre-treatment with E2. MET significantly increased total $P G R$ transcript levels in normal and high glucose conditions by 5 - and 15-fold, respectively, relative to the corresponding non-MET treated levels (Fig. 4A). Interestingly, while MET increased the levels of $P G R-B$ transcripts by 25 -fold in cells grown in normal glucose $+\mathrm{E} 2$, no comparable effects on $P G R-B$ were elicited by MET in cells incubated under high glucose + E2 (Fig. 4B). Given that total $P G R$ transcript levels are the sum of those for $P G R-A+P G R-B$ isoforms, the relative changes in $P G R-A$ and $P G R-B$ expression under normal glucose $\pm \mathrm{E} 2$ and high glucose $\pm \mathrm{E} 2$ conditions were determined from the $P G R-B / P G R$ transcript expression ratios. Under normal glucose conditions, the increase in $P G R$ expression with MET + E2 was due to increased $P G R-B$ transcript levels (Fig. 4C, left panel). Under high glucose conditions, MET decreased the ratio of $P G R-B / P G R$ transcripts in the presence or absence of E2, suggesting that levels of $P G R-A$ transcripts are increased by treatment with MET under high glucose conditions (Fig. 4C, right panel).
Reduced KLF9 expression promotes PGR-A transcription in E2/MET-treated cells independent of glucose environment. Our previous study showed that human endometrial tumors display lower levels of the tumor suppressor protein KLF9 compared with those in the adjacent non-tumor endometrial tissue (21). These findings suggest that loss of KLF9 expression is a feature of EC cells and that the antiproliferative effects of MET in the context of normal glucose (Fig. 2A and C) may be partly due to the induction of KLF9 expression. To test the latter hypothesis, $K L F 9$ transcript levels and those of its family member Krüppel-like factor 4 (KLF4) were measured in E2/MET-treated cells. Under normal glucose conditions, MET or E2 alone had no effect on $K L F 9$ transcript levels (Fig. 5A). With MET-treatment, KLF9 mRNA levels were modestly decreased by E2, which contrasted with the increase noted under high glucose conditions (Fig. 5A). KLF4 mRNA levels were unresponsive to MET, alone or with E2, in normal and high glucose conditions (Fig. 5B).

We previously reported that in E2-treated Ishikawa cells, $K L F 9$ siRNA increased total $P G R$ transcript levels (27). In the context of E2/MET treatments (Fig. 1), the transfection of Ishikawa cells with KLF9 siRNA promoted total PGR expression in both normal and high glucose culture conditions (Fig. 6). Parallel changes in $P G R-B$ transcript levels were not observed when $K L F 9$ expression was reduced, indicating increased levels of $P G R-A$ transcripts.

MPA-mediated downregulation of PGR expression is greater with MET treatment under high compared with normal glucose conditions. Treatment with progestins can often lead to resistance over time due to progestin-mediated downregulation and/or desensitization of its receptor $(28,29)$. To determine if MET alters the progestin sensitivity of EC cells by inhibiting PGR downregulation, cells were treated 


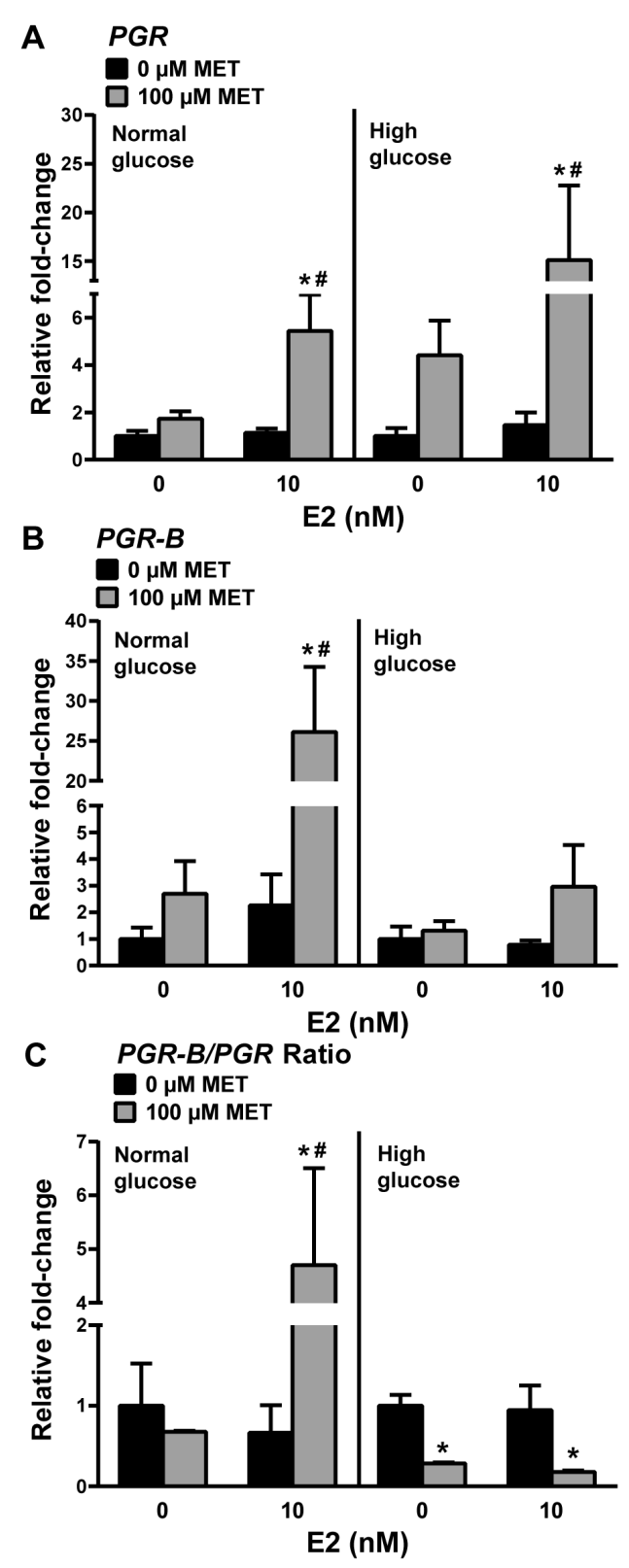

Figure 4. MET differentially increases PGR isoform transcript levels in E2-treated Ishikawa cells under normal and high glucose culture conditions. Ishikawa cells cultured in normal or high glucose conditions were treated with $(10 \mathrm{nM})$ or without $(0 \mathrm{nM}) \mathrm{E} 2$ and then with $(100 \mu \mathrm{M})$ or without $(0 \mu \mathrm{M})$ MET twice at 24-h intervals. Cells were collected $24 \mathrm{~h}$ after the last MET treatment and evaluated for (A) $P G R$ and (B) $P G R-B$ RNA levels by reverse transcription-quantitative PCR. TATA-binding protein and $\beta$-actin mRNAs were used as normalization controls. (C) Ratios of $P G R-B$ transcripts to total $P G R$ transcripts were determined from values obtained in panels (A) and (B) under each experimental condition. Data are presented as mean $\pm \operatorname{SEM}(n=6)$ and expressed as the fold change from the corresponding control (0 nM E2 and $0 \mu \mathrm{M}$ MET). ${ }^{*} \mathrm{P}<0.05$ vs. $0 \mu \mathrm{M}$ MET, ${ }^{*} \mathrm{P}<0.05$ vs. $0 \mathrm{nM}$ E2, as determined by two-way analysis of variance followed by Tukey's test. MET, metformin; E2, 17 $\beta$-estradiol; PGR, progesterone receptor.

with MPA after exposure to E2/MET in normal and high glucose environments. KLF9 mRNA levels were not altered by MPA co-treatment under normal and high glucose conditions. Total PGR mRNA levels were significantly decreased by MPA under high glucose but not normal glucose conditions (Fig. 7). Notably, no corresponding changes in $P G R-B$ transcript levels were noted under either glucose condition. These results
A $\quad K L F 9$
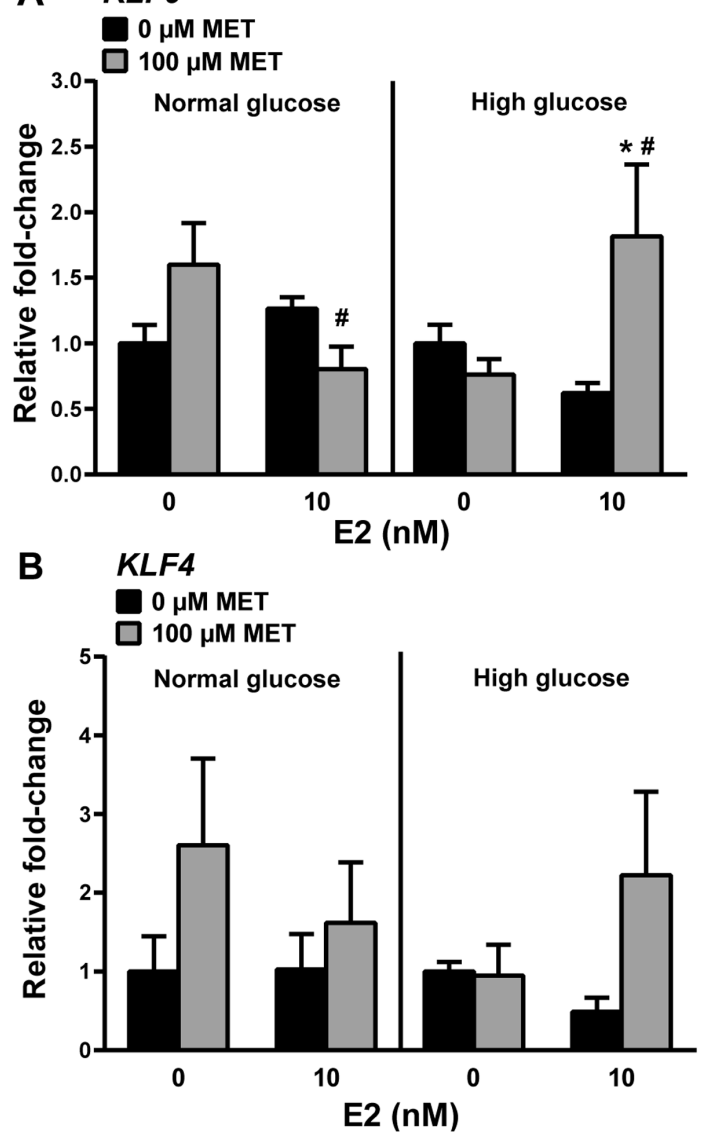

Figure 5. MET has no effect on KLF9 and 4 transcript levels in Ishikawa cells under normal glucose conditions. Ishikawa cells cultured under normal or high glucose conditions were treated with $10 \mathrm{nM}$ E2 or vehicle control $(0 \mathrm{nM} \mathrm{E} 2)$, and then with $(100 \mu \mathrm{M})$ or without $(0 \mu \mathrm{M})$ MET twice at 24-h intervals. Cells were collected $24 \mathrm{~h}$ after the last MET treatment and evaluated for (A) $K L F 9$ and (B) $K L F 4$ RNA levels by reverse transcription-quantitative PCR. TATA-binding protein and $\beta$-actin mRNAs were used as normalization controls. Data are presented as mean $\pm \operatorname{SEM}(n=6)$ and are expressed as fold-change from the corresponding control ( $0 \mathrm{nM}$ E2 and $0 \mu \mathrm{M}$ MET). ${ }^{*} \mathrm{P}<0.05$ vs. $0 \mu \mathrm{M}$ MET; ${ }^{\#} \mathrm{P}<0.05$ vs. $0 \mathrm{nM}$ E2, as determined by two-way analysis of variance followed by Tukey's test. MET, metformin; E2, $17 \beta$-estradiol; KLF, Krüppel-like factor.

suggest that MET promotes the MPA-induced downregulation of $P G R-A$ mRNA under high glucose conditions.

MET effects on PGR gene expression are partly $A M P K$-dependent. In EC cells, supra-physiological doses of MET have been shown to activate AMPK, leading to inhibition of the mTOR signaling pathway and resulting in decreased cellular protein synthesis and proliferation (30-32). To determine whether the effects of physiologically relevant doses of MET on PGR signaling under normal glucose conditions are mediated by the AMPK pathway, PGR expression levels in the presence of the AMPK inhibitor Compound C (33) were evaluated. Consistent with the aforementioned data (Fig. 4A and B), the MET-induced increase in transcript levels for total PGR, while significant, was less robust than that for $P G R-B(\sim 5-$ vs. $\sim 12$-fold). Moreover, while there was a marked reduction in $P G R-B$ expression with Compound C, no significant reduction was found in total $P G R$ expression (Fig. 8A). When cells were treated with AICAR, an AMPK-activator (34), instead 

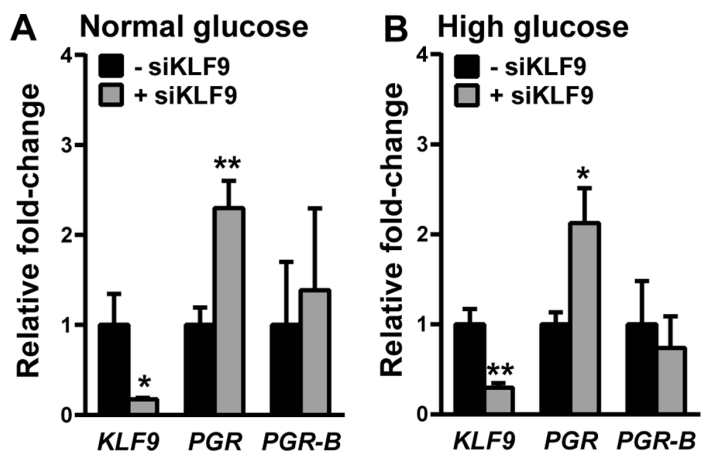

Figure 6. Loss of KLF9 expression promotes the induction of PGR-A transcript levels in E2/MET-treated Ishikawa cells under normal and high glucose culture conditions. Ishikawa cells cultured in (A) normal or (B) high glucose conditions were transfected with scrambled siRNA or siKLF9 prior to sequential E2 and MET treatments. Cells were collected $24 \mathrm{~h}$ after the last MET treatment and evaluated for levels of the indicated mRNAs by reverse transcription-quantitative PCR. TATA-binding protein and $\beta$-actin mRNAs were used as normalization controls. Data are presented as mean $\pm \operatorname{SEM}(n=6)$ and are expressed as fold-change from the corresponding control (-siKLF9). ${ }^{*} \mathrm{P}<0.05$ and ${ }^{* *} \mathrm{P}<0.01$ vs. scrambled siRNA, as determined by Student's t-test. MET, metformin; E2, 17ß-estradiol; siRNA, small interfering RNA; siKLF9, siRNA targeting Krüppel-like factor 9.
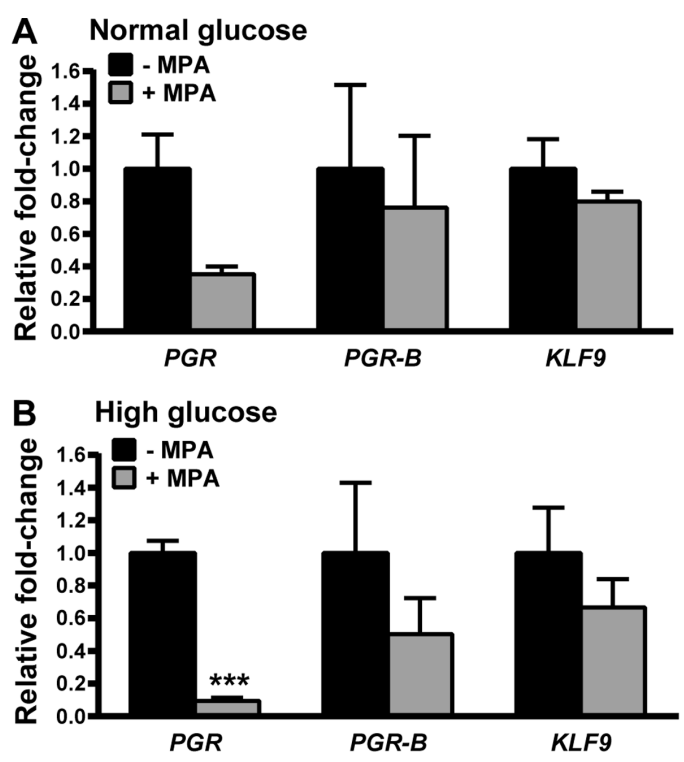

Figure 7. PGR-A transcript levels are preferentially downregulated by MPA in E2/MET-treated cells under high glucose conditions. Ishikawa cells cultured in (A) normal and (B) high glucose conditions were treated with E2 $(10 \mathrm{nM})$ and then with MET twice $(100 \mu \mathrm{M})$ at $24-\mathrm{h}$ intervals. The cells with subsequently treated with vehicle or MPA $(1 \mu \mathrm{M})$. Cells were collected $24 \mathrm{~h}$ later and evaluated for levels of the indicated mRNAs by reverse transcription-quantitative PCR. TATA-binding protein and $\beta$-actin mRNAs were used as normalization controls. Data are presented as mean \pm SEM $(n=6)$ and are expressed as fold-change from the corresponding control (-MPA). ${ }^{* * *} \mathrm{P}<0.001$ vs. vehicle, as determined by Student's t-test. MET, metformin; E2, 17ß-estradiol; PGR, progesterone receptor; KLF, Krüppel-like factor; MPA, MPA, medroxyprogesterone acetate.

of MET, transcript levels of $P G R-B$ but not total $P G R$ were increased (Fig. 8B), albeit the fold increase ( 4-fold) was lower compared with that achieved with MET ( 25-fold; Fig. 4B). However, AICAR demonstrated a broader range of gene targets with increased levels of estrogen receptor 2 (ESR2), KLF9 and KLF4 (Fig. 8B), which were not significantly affected by MET
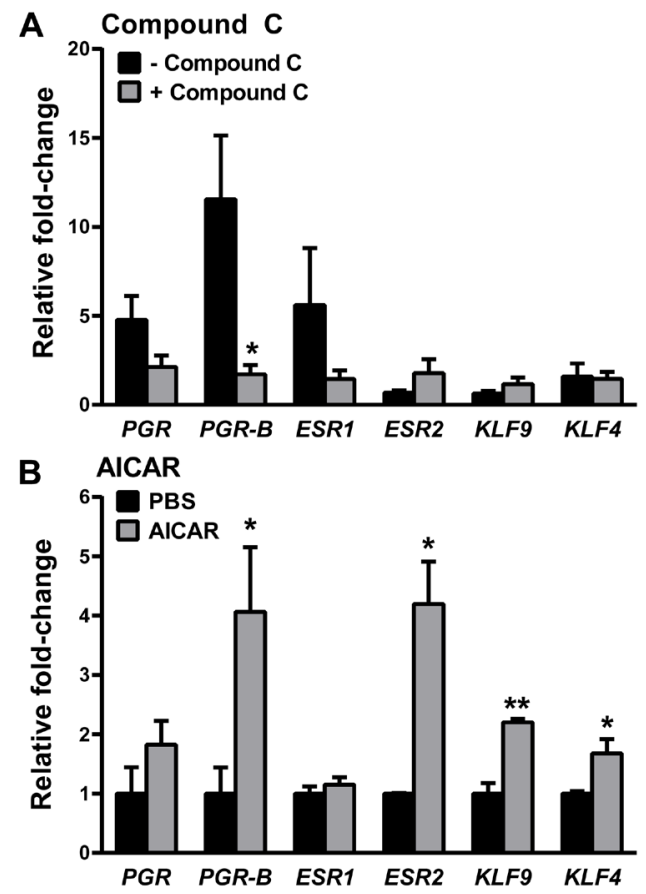

Figure 8. MET targeting of $P G R-B$ expression in Ishikawa cells is partly AMPK-dependent. (A) Ishikawa cells grown in normal glucose conditions were treated with E2 and then with MET \pm Compound C. Cells were collected $24 \mathrm{~h}$ after the last MET treatment and evaluated for levels of the indicated mRNAs by reverse transcription-quantitative PCR. TATA-binding protein and $\beta$-actin mRNAs were used as normalization controls. Data are presented as mean \pm SEM $(n=6)$ and are expressed as fold-change of MET treatment over the corresponding control (without MET). ${ }^{*} \mathrm{P}<0.05$ vs. vehicle control (-Compound C), as determined by Student's t-test. (B) Ishikawa cells grown in normal glucose conditions were treated with E2 and then with AMPK activator AICAR $(500 \mu \mathrm{M})$ twice at 24-h intervals in place of MET. Collected cells were analyzed as in (A). Data are presented as mean \pm SEM $(n=6)$ and are expressed as fold change from the corresponding vehicle control (PBS). ${ }^{*} \mathrm{P}<0.05$ and $^{* *} \mathrm{P}<0.01$ vs. PBS, as determined by Student's t-test. MET, metformin; E2, 17 $\beta$-estradiol; PGR, progesterone receptor; AMPK, AMP-activated protein kinase; ESR, estrogen receptor; KLF, Krüppel-like factor; AICAR, 5-aminoimidazole-4-carboxamide ribonucleotide.

(Fig. 5 for $K L F 9$ and KLF4; ESR2, data not shown) and by the inhibition of MET-mediated AMPK signaling (Fig. 8A).

\section{Discussion}

MET as an adjuvant in cancer treatments is increasingly gaining support, based on population studies demonstrating a reduction in cancer incidence and mortality in patients with type 2 diabetes taking MET (7). Nevertheless, the benefit of MET in the management of EC remains largely unknown, given limited clinical studies to date and the lack of an established causal relationship between physiologically relevant MET exposure and the EC genotype and phenotype in patients within normal and diabetic glucose ranges. The present study compared the proliferation, stem cell-like growth/self-renewal and expression of selected genes in the well-differentiated Ishikawa EC cell line treated with E2 and exposed to physiologically-relevant $\operatorname{MET}$ doses $(\mu \mathrm{M})$ in the presence of normal and high concentrations of glucose. The results showed that MET reduced EC cell numbers and spheroid formation under normal glucose conditions, and that these MET-elicited changes were lost when glucose levels 


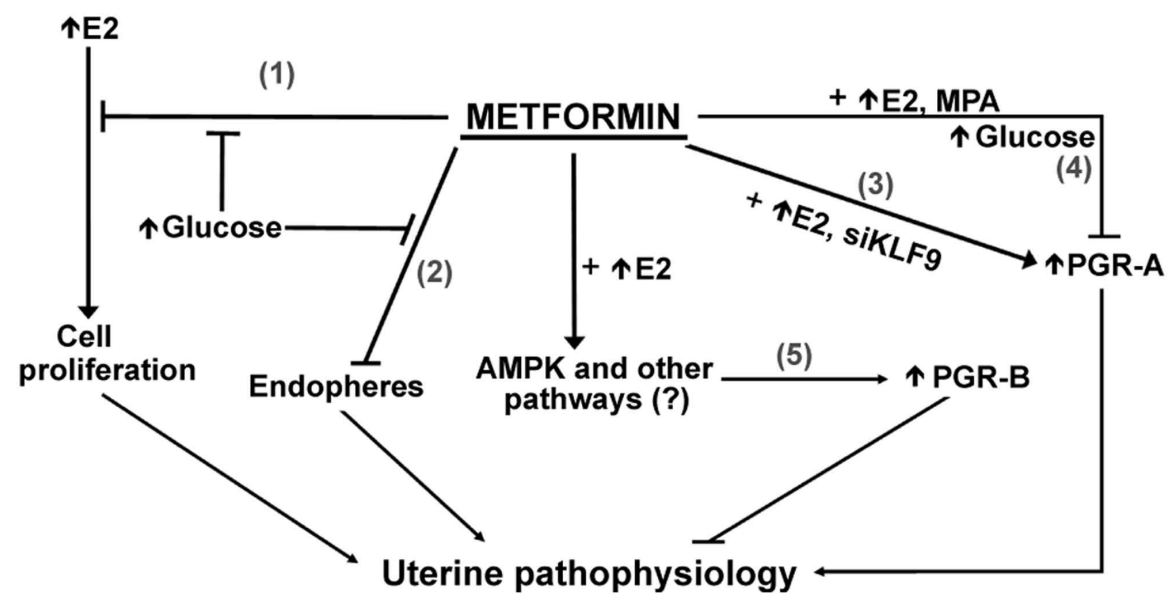

Figure 9. Schematic diagram summarizing the proposed effects of MET on endometrial carcinoma cells under normal and high glucose conditions. Pathways (1) and (2) are influenced by MET under normal but not high glucose conditions. The MET-induced increase of $P G R-B$ transcript levels is lost in Ishikawa cells under normal or high glucose conditions when $K L F 9$ expression is reduced via pathway (3); instead, induction of $P G R-A$ transcript levels is observed. Pathway (4) depicts MET-mediated inhibition of $P G R$ - $A$ expression in response to MPA administration under high glucose. Induction of $P G R-B$ expression by MET is mediated by AMP-activated protein kinase and other yet unknown pathways (5). Lines with an arrowhead and with a blocked bar represent pathway promotion and inhibition, respectively. MET, metformin; E2, 17ß-estradiol; PGR, progesterone receptor; MPA, MPA, medroxyprogesterone acetate; siKLF9, siRNAtargeting Krüppel-like factor 9.

were elevated. The reduction in $C N N D 1$ transcript levels and the inhibition of stem cell-like activity with MET in normal but not high glucose conditions, respectively indicate that MET has inhibitory effects on EC cell cycle progression and metastatic potential $(25,35)$, which predict better outcomes with MET in non-diabetic patients with EC compared with their diabetic counterparts. Moreover, it was found that while MET increased total $P G R$ transcript levels, irrespective of the level of glucose exposure, MET preferentially induced $P G R-B$ transcript levels under normal glucose conditions, and conversely, those of $P G R-A$ under high glucose conditions. These findings suggest that in non-diabetic compared with diabetic patients with EC, MET may elicit distinct effects on progestin signaling, which differ according to their mediation by PGR-B and PGR-A isoforms. A role for MET in progestin signaling is supported by a previous study demonstrating that the $\mathrm{PI} 3 \mathrm{~K} / \mathrm{AKT} / \mathrm{mTOR}$ pathway promotes progestin resistance in EC cells (22). Furthermore, the present study showed that the ability of MET to enhance progestin signaling via the induction of $P G R-B$ transcript levels in EC cells is partly but not entirely dependent on AMPK activation. The present results indicate that the direct effects of MET on EC are cellular context-dependent, and suggest that the potential use of MET as an adjuvant in EC management involving progestin therapy may involve its induction of $P G R-B$ expression via AMPK and other yet unknown signaling pathways.

The present study modeled the effects of MET in non-diabetic and diabetic patients with EC using MEM (normal glucose) and DMEM (high glucose), respectively. While MEM and DMEM have differences in several constituents, including their levels of vitamins and amino acids, the major difference is their respective glucose concentrations, which we hypothesize to have more consequential effects on cellular metabolic status. In a previous study to evaluate the effects of MET in EC cells, MEM and DMEM were similarly used to mimic normal and hyper-insulinemic conditions (36). However, the present results are likely to be more physiologically relevant, since the MET doses used were in the $\mu \mathrm{M}$ range rather than the supra-physiological (mM) doses used in earlier studies $(22,23)$. The present findings align with those reported in triple-negative breast cancer cell lines wherein the antiproliferative effects of MET were enhanced and inhibited in glucose-starved and glucose-excess conditions, respectively (10). The present study also found that the formation of EC cell spheroids, referred to as endospheres and considered to display cancer stem cell-like activity and metastatic potential $(25,35)$, was differentially responsive to MET, dependent on cellular glucose. MET alone was shown to inhibit endosphere growth $(\mathrm{P} 1)$ and regeneration $(\mathrm{P} 2)$ under normal glucose conditions. By contrast, under high glucose conditions, Ishikawa spheroid formation was unresponsive to MET, paralleling the lack of MET-elicited antiproliferative response for these cells. MET-induced inhibition of spheroid growth in the presence of a normal glucose concentration has been similarly demonstrated in breast, ovarian and colon cancer cell lines (37). Currently, there is no explanation for the E2-induced abrogation of the effects of MET on the formation of spheroids under normal glucose conditions, given that endometrial epithelial stem/progenitor cells are reported to lack estrogen receptor expression (38).

The in vivo relevance of PGR signaling as a MET target is supported by our previous study showing the induction of total PGR protein levels in the endometrial tumors of non-diabetic patients with EC following short-term pre-surgical MET treatment (13). The present study reports the novel finding that changes in glucose conditions modify the effects of MET on PGR signaling. While MET increased total $P G R$ transcript levels, irrespective of the glucose environment, MET under normal glucose conditions preferentially induced $P G R-B$ isoform transcript levels, whereas under high glucose conditions it increased $P G R-A$ isoform transcript levels. Given the pro-differentiation activity of PGR-B and the function of PGR-A as a repressor of PGR-B transcriptional activity (39), changes in their expression ratios can significantly impact 
EC phenotype and gene signaling networks. Thus, the loss of inhibitory effects of MET on cell proliferation and endosphere formation in the presence of high concentrations of glucose may reflect the less-differentiated state of EC cells as a consequence of predominant PGR-A isoform activity. Another study also reported the upregulation of $P G R-B$ mRNA and protein levels by MET, albeit at supra-physiological doses, in Ishikawa and HEC-1A cells under normal glucose conditions (40). Given that MET-responsive Ishikawa cells express PGR, we postulate that this mechanism of MET will not be applicable to triple-negative breast cancer cells, further affirming the pleiotropic context-dependent signaling of MET in distinct cancer types. While the PGR-A and PGR-B protein levels corresponding to changes in the $P G R-B$ and $P G R-A$ isoform transcript levels were not quantified in the present study, previous studies $(27,41,42)$ have demonstrated that changes in the respective $P G R$ transcript levels are closely recapitulated in their protein levels and transcriptional activity.

The influence of the glucose environment on the ability of MET to modify EC cell response, based on two parameters related to PGR signaling, namely KLF9 expression and response to MPA administration, was evaluated. Our previous study showed that KLF9 is a PGR-B interacting protein $(43,44)$ and that human EC tumors demonstrate loss of KLF9 expression (21). The present study found that the transfection of Ishikawa cells with siKLF9, under conditions resulting in the reduction of KLF9 protein levels (13), caused an increase in total $P G R$ transcript levels without a corresponding change in $P G R-B$ transcript levels, under normal and high glucose conditions. The indicated increase in $P G R-A$ isoform transcript levels with reduced $K L F 9$ expression suggests that in more advanced tumors, in which $K L F 9$ expression is already significantly attenuated, MET may not positively affect EC outcome, irrespective of the glucose environment. In the context of MPA administration and a high glucose environment, MET appeared to amplify the reduction of $P G R-A$ isoform levels, given the lack of change in $P G R-B$ isoform transcript levels. Whether the increase in $P G R-B$ relative to $P G R$ - $A$ expression with MPA/MET treatments is functionally consequential to EC remains to be determined. However, in a previous study the treatment of Ishikawa cells expressing only PGR-B with progestin resulted in complete growth inhibition, while those expressing only PGR-A showed only $50 \%$ growth inhibition (45). Thus, by favoring the expression of $P G R-B$ over $P G R-A$ under high glucose conditions, MET may synergize with MPA to increase progestin-sensitivity and thereby favor cell differentiation at the expense of cell proliferation, with significant relevance to progestin therapy for patients with EC.

Using two pharmacological agents, namely Compound $\mathrm{C}$ and AICAR, to inhibit and stimulate AMPK-signaling, respectively, a substantial reduction $(\sim 90 \%)$ of $P G R-B$ expression with Compound $\mathrm{C}$ and more modest induction of $P G R-B$ transcript levels with AICAR were demonstrated. Indeed, the induction of $P G R-B$ transcript levels by AICAR ( $\sim 5$-fold) is $\sim 2$-fold lower in magnitude than that by MET (12-15-fold), suggesting that MET may utilize other pathways to promote $P G R-B$ transcript levels. In this regard, Compound $\mathrm{C}$ has been reported to inhibit the activities of other kinases, in addition to AMPK, suggesting a role for MET in the regula- tion of multiple kinase activities in target cells. The ability of AICAR to increase $E S R 2, K L F 9$ and $K L F 4$ transcript levels in the absence of similar effects by MET under the same experimental conditions (Fig. 5; data not shown for ESR2) may be attributable to pathways other than AMPK that have been implicated in AICAR signaling $(46,47)$. Taken together, the present results are suggestive of AMPK-dependent and -independent actions of MET on EC cells, as has been shown for other systems such as T cells, retinal epithelial cells and mouse embryonic fibroblasts $(46,48)$, which may contribute to the preferential inductive effect of MET on $P G R-B$ transcript levels.

In conclusion, the present study underscores the context-dependent effects of MET in its selective targeting of $P G R-B$ isoform transcript levels in EC cells (Fig. 9). Given the current global pandemic of diabetes and the increasing focus on MET as a viable adjuvant for cancer management, it is essential to understand the context underlying the favorable effects of MET on EC. The present data indicate that the PGR signaling pathway may constitute an important and novel MET target to increase the progestin sensitivity of EC cells. This may provide an opportunity for the early prevention of EC and other progestin-dependent gynecological pathologies in women with increased risks.

\section{Acknowledgements}

Not applicable.

\section{Funding}

This study was funded by the University of the Philippines Office of the Vice-President for Academic Affairs-Emerging Interdisciplinary Research (grant no. EIDR-C08-006-MCV/RCMS), the University of Arkansas Barton Endowment Funds (RCMS) and the National Institutes of Health (RCMS; grant no. RO1HD21961). Training and internship (SJUS) were sponsored by the University of the Philippines Office of Internet Linkages-Continuous Operational and Outcomes-Bases Partnership for Excellence in Research and Academic Training Enhancement and the Department of Science and Technology Accelerated Science and Technology Human Resource Development Program National Science Consortium, Philippines. IA is a recipient of the 2019 Summer Fellowship from The Endocrine Society (USA).

\section{Availability of data and materials}

The datasets used and/or analyzed during the present study are available from the corresponding author on reasonable request.

\section{Authors' contributions}

RCMS and MCV supervised the study; SJUS, RCMS and MCV conceived and designed the experiments; SJUS performed the experiments; SJUS and IA analyzed the data; SJUS, RCMS and MCV wrote the manuscript; SJUS, IA, RCMS and MCV revised the manuscript. All authors read and approved the final manuscript. 


\section{Ethics approval and consent to participate}

Not applicable.

\section{Patient consent for publication}

Not applicable.

\section{Competing interests}

The authors declare that they have no competing interests.

\section{References}

1. Howlader N, Noone AM, Krapcho M, Miller D, Brest A, Yu M Ruhl J, Tatalovich Z, Mariotto A, Lewis DR, et al (eds): SEER Cancer Statistics Review, 1975-2017, based on November 2019 SEER data submission. National Cancer Institute, Bethesda, MD 2020. https://seer.cancer.gov/csr/1975_2017/. Accessed April 15, 2020.

2. Friberg E, Mantzoros CS and Wolk A: Diabetes and risk of endometrial cancer: A population-based prospective cohort study. Cancer Epidemiol Biomarkers Prev 16: 276-280, 2007.

3. Kitson SJ, Evans DG and Crosbie EJ: Identifying high-risk women for endometrial cancer prevention strategies: Proposal of an endometrial cancer risk prediction model. Cancer Prev Res (Phila) 10: 1-13, 2017.

4. Ohkuma T, Peters SAE and Woodward M: Sex differences in the association between diabetes and cancer: A systematic review and meta-analysis of 121 cohorts including 20 million individuals and one million events. Diabetologia 61: 2140-2154, 2018.

5. Saeedi P, Petersohn I, Salpea P, Malanda B, Karuranga S, Unwin N, Colagiuri S, Guariguata L, Motala AA, Ogurtsova K, et al; IDF Diabetes Atlas Committee: Global and regional diabetes prevalence estimates for 2019 and projections for 2030 and 2045: Results from the International Diabetes Federation Diabetes Atlas, 9th edition. Diabetes Res Clin Pract 157: 107843, 2019

6. Abarca-Gómez L, Abdeen ZA, Hamid ZA, Abu-Rmeileh NM, Acosta-Cazares B, Acuin C, Adams RJ, Aekplakorn W, Afsana K, Aguilar-Salinas CA, et al; NCD Risk Factor Collaboration (NCD-RisC): Worldwide trends in body-mass index, underweight, overweight, and obesity from 1975 to 2016: A pooled analysis of 2416 population-based measurement studies in 128.9 million children, adolescents, and adults. Lancet 390 $2627-2642,2017$

7. Roshan MH, Shing YK and Pace NP: Metformin as an adjuvant in breast cancer treatment. SAGE Open Med 7: 2050312119865114 , 2019.

8. Davies G,Lobanova L,Dawicki W, Groot G, Gordon JR, Bowen M, Harkness T and Arnason T: Metformin inhibits the development, and promotes the resensitization, of treatment-resistant breast cancer. PLoS One 12: e0187191, 2017.

9. Shi P, Liu W, Tala, Wang H, Li F, Zhang H, Wu Y, Kong Y, Zhou Z, Wang C, et al: Metformin suppresses triple-negative breast cancer stem cells by targeting KLF5 for degradation. Cell Discov 3: 17010, 2017.

10. Varghese S, Samuel SM, Varghese E, Kubatka $P$ and Büsselberg D: High Glucose Represses the Anti-Proliferative and Pro-Apoptotic Effect of Metformin in Triple Negative Breast Cancer Cells. Biomolecules 9: 16, 2019.

11. Ariaans G, Jalving M, Vries EG and Jong S: Anti-tumor effects of everolimus and metformin are complementary and glucose-dependent in breast cancer cells. BMC Cancer 17: 232 , 2017.

12. Oliveras-Ferraros C, Vazquez-Martin A, Cuyàs E, Corominas-Faja B, Rodríguez-Gallego E, Fernández-Arroyo S, Martin-Castillo B, Joven J and Menendez JA: Acquired resistance to metformin in breast cancer cells triggers transcriptome reprogramming toward a degradome-related metastatic stem-like profile. Cell Cycle 13: 1132-1144, 2014.

13. Pabona JMP, Burnett AF, Brown DM, Quick CM, Simmen FA, Montales MTE, Liu SJ, Rose T, Alhallak I, Siegel ER, et al: Metformin Promotes Anti-tumor Biomarkers in Human Endometrial Cancer Cells. Reprod Sci 27: 267-277, 2020.
14. Soliman PT, Zhang Q, Broaddus RR, Westin SN, Iglesias D, Munsell MF, Schmandt R, Yates M, Ramondetta L and Lu KH: Prospective evaluation of the molecular effects of metformin on the endometrium in women with newly diagnosed endometrial cancer: A window of opportunity study. Gynecol Oncol 143: 466-471, 2016.

15. Laskov I, Drudi L, Beauchamp M-C, Yasmeen A, Ferenczy A, Pollak M and Gotlieb WH: Anti-diabetic doses of metformin decrease proliferation markers in tumors of patients with endometrial cancer. Gynecol Oncol 134: 607-614, 2014.

16. Caillé G, Lacasse Y, Raymond M, Landriault H, Perrotta M, Picirilli G, Thiffault J and Spénard J: Bioavailability of metformin in tablet form using a new high pressure liquid chromatography assay method. Biopharm Drug Dispos 14: 257-263, 1993.

17. Wilcock $C$ and Bailey CJ: Accumulation of metformin by tissues of the normal and diabetic mouse. Xenobiotica 24: 49-57, 1994.

18. Martin-Castillo B, Vazquez-Martin A, Oliveras-Ferraros C and Menendez JA: Metformin and cancer: Doses, mechanisms and the dandelion and hormetic phenomena. Cell Cycle 9: 1057-1064, 2010.

19. Pabona JM, Simmen FA, Nikiforov MA, Zhuang D, Shankar K, Velarde MC, Zelenko Z, Giudice LC and Simmen RC: Krüppel-like factor 9 and progesterone receptor coregulation of decidualizing endometrial stromal cells: Implications for the pathogenesis of endometriosis. J Clin Endocrinol Metab 97: E376-E392, 2012.

20. Livak KJ and Schmittgen TD: Analysis of relative gene expression data using real-time quantitative PCR and the $2(-\Delta \Delta$ C(T)) method. Methods 25: 402-408, 2001

21. Simmons CD, Pabona JM, Heard ME, Friedman TM, Spataro MT, Godley AL, Simmen FA, Burnett AF and Simmen RC: Krüppel-like factor 9 loss-of-expression in human endometrial carcinoma links altered expression of growth-regulatory genes with aberrant proliferative response to estrogen. Biol Reprod 85: 378-385, 2011.

22. Liu Z, Qi S, Zhao X, Li M, Ding S, Lu J and Zhang H: Metformin inhibits $17 \beta$-estradiol-induced epithelial-to-mesenchymal transition via $\beta K$ lotho-related ERK1/2 signaling and AMPK $\alpha$ signaling in endometrial adenocarcinoma cells. Oncotarget 7: 21315-21331, 2016.

23. Zhang J, Xu H, Zhou X, Li Y, Liu T, Yin X and Zhang B: Role of metformin in inhibiting estrogen-induced proliferation and regulating $E R \alpha$ and $E R \beta$ expression in human endometrial cancer cells. Oncol Lett 14: 4949-4956, 2017.

24. Deane JA, Cousins FL and Gargett CE: Endometrial organoids: in vitro models for endometrial research and personalized medicine. Biol Reprod 97: 781-783, 2017.

25. Kitson SJ, Rosser M, Fischer DP, Marshall KM, Clarke RB and Crosbie EJ: Targeting endometrial cancer stem cell activity with metformin is inhibited by patient-derived adipocyte-secreted factors. Cancers (Basel) 11: 653, 2019

26. Hirsch HA, Iliopoulos D, Tsichlis PN and Struhl K: Metformin selectively targets cancer stem cells, and acts together with chemotherapy to block tumor growth and prolong remission. Cancer Res 69: 7507-7511, 2009.

27. Velarde MC,Zeng Z,McQuown JR,SimmenFA and Simmen RCM: Kruppel-like factor 9 is a negative regulator of ligand-dependent estrogen receptor $\alpha$ signaling in Ishikawa endometrial adenocarcinoma cells. Mol Endocrinol 21: 2988-3001, 2007.

28. Kim JJ and Chapman-Davis E: Role of progesterone in endometrial cancer. Semin Reprod Med 28: 81-90, 2010.

29. Wang Y, Wang Y, Zhang Z, Park JY, Guo D, Liao H, Yi X, Zheng Y, Zhang D, Chambers SK, et al: Mechanism of progestin resistance in endometrial precancer/cancer through Nrf2-AKR1C1 pathway. Oncotarget 7: 10363-10372, 2016.

30. Cantrell LA, Zhou C, Mendivil A, Malloy KM, Gehrig PA and Bae-Jump VL: Metformin is a potent inhibitor of endometrial cancer cell proliferation--implications for a novel treatment strategy. Gynecol Oncol 116: 92-98, 2010.

31. Hanna RK, Zhou C, Malloy KM, Sun L, Zhong Y, Gehrig PA and Bae-Jump VL: Metformin potentiates the effects of paclitaxel in endometrial cancer cells through inhibition of cell proliferation and modulation of the mTOR pathway. Gynecol Oncol 125: 458-469, 2012

32. Viollet B, Guigas B, Sanz Garcia N, Leclerc J, Foretz M and Andreelli F: Cellular and molecular mechanisms of metformin: An overview. Clin Sci (Lond) 122: 253-270, 2012.

33. Zhou G, Myers R, Li Y, Chen Y, Shen X, Fenyk-Melody J, Wu M, Ventre J, Doebber T, Fujii N, et al: Role of AMP-activated protein kinase in mechanism of metformin action. J Clin Invest 108: $1167-1174,2001$. 
34. Corton JM, Gillespie JG, Hawley SA and Hardie DG: 5-aminoimidazole-4-carboxamide ribonucleoside. A specific method for activating AMP-activated protein kinase in intact cells? Eur J Biochem 229: 558-565, 1995.

35. Carvalho MJ, Laranjo M, Abrantes AM, Casalta-Lopes J, Sarmento-Santos D, Costa T, Serambeque B, Almeida N, Gonçalves T, Mamede C, et al: Endometrial Cancer Spheres Show Cancer Stem Cells Phenotype and Preference for Oxidative Metabolism. Pathol Oncol Res 25: 1163-1174, 2019.

36. de Barros Machado A, Dos Reis V, Weber S, Jauckus J, Brum IS, von Eye Corleta H, Strowitzki T, Capp E and Germeyer A: Proliferation and metastatic potential of endometrial cancer cells in response to metformin treatment in a high versus normal glucose environment. Oncol Lett 12: 3626-3632, 2016.

37. Hu T, Chung YM, Guan M, Ma M, Ma J, Berek JS and Hu MCT: Reprogramming ovarian and breast cancer cells into non-cancerous cells by low-dose metformin or SN-38 through FOXO3 activation. Sci Rep 4: 5810, 2014

38. Janzen DM, Cheng D, Schafenacker AM, Paik DY, Goldstein AS, Witte ON, Jaroszewicz A, Pellegrini M and Memarzadeh S: Estrogen and progesterone together expand murine endometrial epithelial progenitor cells. Stem Cells 31: 808-822, 2013.

39. Vegeto E, Shahbaz MM, Wen DX, Goldman ME, O'Malley BW and McDonnell DP: Human progesterone receptor A form is a cell- and promoter-specific repressor of human progesterone receptor B function. Mol Endocrinol 7: 1244-1255, 1993.

40. Xie Y, Wang YL, Yu L, Hu Q, Ji L, Zhang Y and Liao QP: Metformin promotes progesterone receptor expression via inhibition of mammalian target of rapamycin (mTOR) in endometrial cancer cells. J Steroid Biochem Mol Biol 126: 113-120, 2011.

41. Graham JD, Yager ML, Hill HD, Byth K, O'Neill GM and Clarke CL: Altered progesterone receptor isoform expression remodels progestin responsiveness of breast cancer cells. Mol Endocrinol 19: 2713-2735, 2005.

42. Mouttet D, Laé M, Caly M, Gentien D, Carpentier S, Peyro-Saint-Paul H, Vincent-Salomon A, Rouzier R, Sigal-Zafrani B, Sastre-Garau X, et al: Estrogen-Receptor, Progesterone-Receptor and HER2 Status Determination in Invasive Breast Cancer. Concordance between Immuno-Histochemistry and MapQuant ${ }^{\mathrm{TM}}$ Microarray Based Assay. PLoS One 11: e0146474, 2016.
43. Zhang D, Zhang XL, Michel FJ, Blum JL, Simmen FA and Simmen RCM: Direct interaction of the Krüppel-like family (KLF) member, BTEB1, and PR mediates progesterone-responsive gene expression in endometrial epithelial cells. Endocrinology 143: 62-73, 2002.

44. Zhang XL, Zhang D, Michel FJ, Blum JL, Simmen FA and Simmen RCM: Selective interactions of Kruppel-like factor $9 /$ basic transcription element-binding protein with progesterone receptor isoforms A and B determine transcriptional activity of progesterone-responsive genes in endometrial epithelial cells. J Biol Chem 278: 21474-21482, 2003.

45. Smid-Koopman E, Blok LJ, Kühne LCM, Burger CW, Helmerhorst TJM, Brinkmann AO and Huikeshoven FJ: Distinct functional differences of human progesterone receptors A and B on gene expression and growth regulation in two endometrial carcinoma cell lines. J Soc Gynecol Investig 10: 49-57, 2003.

46. Rao E, Zhang Y, Li Q, Hao J, Egilmez NK, Suttles J and Li B: AMPK-dependent and independent effects of AICAR and compound C on T-cell responses. Oncotarget 7: 33783-33795, 2016.

47. Zhao X, Luo G, Cheng Y, Yu W, Chen R, Xiao B, Xiang Y, Feng C, $\mathrm{Fu} \mathrm{W}$, Duan C, et al: Compound C induces protective autophagy in human cholangiocarcinoma cells via Akt/mTOR-independent pathway. J Cell Biochem 119: 5538-5550, 2018.

48. Philippe C, Pinson B, Dompierre J, Pantesco V, Viollet B, Daignan-Fornier B and Moenner M: AICAR Antiproliferative Properties Involve the AMPK-Independent Activation of the Tumor Suppressors LATS 1 and 2. Neoplasia 20: 555-562, 2018.

(c) $(9)$ This work is licensed under a Creative Commons cc) Attribution-NonCommercial-NoDerivatives 4.0 International (CC BY-NC-ND 4.0) License. 